\title{
Transformation of Major Ginsenosides into Minor Ginsenosides in Ginseng by Pickling in Salted Rice Malt Paste
}

\author{
Manabu Sugimoto ${ }^{1 \star}$ and Nobutada Murakami ${ }^{2}$ \\ ${ }^{1}$ Institute of Plant Science and Resources, Okayama University, 2-20-1 \\ Chuo, Kurashiki, Okayama 710-0046, Japan \\ ${ }^{2}$ Functional Food Creation Research Institute Co., Ltd., 4422-1 \\ Yoshikawa, Kibichuo, Kaga, Okayama 716-1241, Japan
}

\author{
*Corresponding author \\ Manabu Sugimoto, Institute of Plant Science and Resources, Okayama \\ University, 2-20-1 Chuo, Kurashiki, Okayama 710-0046, Japan.
}

Submitted: 25 May 2020; Accepted: 29 May 2020; Published: 05 Jun 2020

\begin{abstract}
Increasing the content of minor ginsenosides in ginseng enhances its pharmaceutical activities. For this study, minor ginsenosides $F 2$ and $C K$ were produced in ginseng by pickling in a salted rice malt paste fermented using Aspergillus kawachii. The A. kawachii excluded $\beta$-glucosidase in the culture broth with $125 \mathrm{mU} / \mathrm{mL}$ after $16 d$ cultivation, and hydrolyzed major ginsenoside Rb1 to generate F2 and $C K$ on the pathway $R b 1 \rightarrow R d \rightarrow F 2 \rightarrow C K$. Steamed rice was fermented by $\mathrm{A}$. kawachii with $14 \% \mathrm{NaCl}$ to produce a salted rice malt paste as a pickle bed with $165 \mathrm{mU} / \mathrm{mL}$ of $\beta$-glucosidase. Fresh 1-year-old and 6-year-old ginseng, which had Rb1 and Rd but which had neither F2 nor CK, were pickled in the salted rice malt paste for 28d. The extract showed production of $F 2$ and $C K$, and changed the ratio of $R b 1, R d 2, F 2$, and $C K$ in ginseng.
\end{abstract}

Keywords: $\beta$-Glucosidase, Compound K (CK), Ginsenoside, Salted Rice Malt Paste, Transformation.

\section{Introduction}

Ginseng, the root of Panax ginseng C.A. Meyer, is a traditional herbal medicine that has long been used in Asian countries [1]. Ginseng saponins, known as ginsenosides, are major active compounds responsible for the pharmacological effects of ginseng. The more than 50 ginsenosides which have been identified from ginseng comprise a dammarane backbone with several sugar side chains by $\beta$-configuration $[2,3]$. Ginseng has six major ginsenosides (Rb1, Rb2, Rc, Rd, Re, Rg1), which consist of 80$90 \%$ of total ginsenosides [4]. Especially, Rb1 is present in more than $20 \%$ of all ginsenosides [5]. Reportedly, major ginsenosides are metabolized to the minor ginsenosides $(\mathrm{Rg} 3, \mathrm{Rh} 2, \mathrm{~F} 2, \mathrm{CK})$ by the hydrolyzing activity of intestinal bacteria [5]. Minor ginsenosides show pharmaceutical activities. Among them, particularly CK induces tumor cell apoptosis, inhibition of tumor cell proliferation, attenuation of tumor invasion and metastasis, and anti-inflammatory effects [6-10]. However, the conversion efficiency depends on individual microflora.

Minor ginsenosides have smaller sugar side chains than those of major ginsenosides $[11,12]$. Therefore, hydrolysis of the sugar moieties of the major ginsenosides has been developed by microbial or enzymatic biotransformation. Reportedly, minor ginsenosides are produced from purified major ginsenosides or crude extract of ginseng by purified or crude enzyme from microorganisms or cultured microorganisms [12-24]. However, the biotransformation efficiency depends on the substrate specificity of the enzyme. In fact, most microorganisms used for transformation are not of food production grade. Preparation of the extract of ginseng and enzyme solution costs time and money.

This study revealed that Aspergillus kawachii, which is used as koji mold for food fermentation in Japan excretes $\beta$-glucosidase to the culture medium well with glucose as the carbon source, thereby hydrolyzing $\mathrm{Rb} 1$ to produce $\mathrm{F} 2$ and $\mathrm{CK}$ through the hydrolyzing pathway of $\mathrm{Rb} 1 \rightarrow \mathrm{Rd} \rightarrow \mathrm{F} 2 \rightarrow \mathrm{CK}$. Ginseng pickled in a salted rice malt paste and fermented by $A$. kawachii for $28 \mathrm{~d}$ contains F2 and $\mathrm{CK}$ and changed the ratio of $\mathrm{Rb} 1, \mathrm{Rd}, \mathrm{F} 2$, and $\mathrm{CK}$ [25].

\section{Materials and Methods}

Materials

One-year-old and 6-year-old ginseng, Panax ginseng C.A. Meyer, were obtained from Yuushien Agrifarm Co., Ltd., Shimane, Japan. Ginsenoside Rb1, Rd, and F2 were purchased from LKT Laboratories, Inc. (USA). Also, CK was obtained from MedChem Express LLC (USA). All other chemicals were of analytical and HPLC reagent grade.

Preparation of Culture Broth and Salted Rice Malt Paste Strains of Aspergillus oryzae Cohn var. oryzae (NBRC 30113), A. sojae Sakaguchi \& Yamada (NBRC 4239), A. kawachii Kitahara \& Yoshida (NBRC 4308), and A. luchuensis Inui (NBRC 4314) were obtained from the NITE Biological Resource Center (Tsukuba, Japan). After the strains were inoculated in media consisting of $0.2 \% \mathrm{NaNO}_{3}, 0.2 \% \mathrm{KCl}, 0.1 \% \mathrm{KH}_{2} \mathrm{PO}_{4}, 0.1 \%$ $\mathrm{NH}_{4} \mathrm{NO}_{3}, 0.1 \% \mathrm{NH}_{4} \mathrm{H}_{2} \mathrm{PO}_{4}, 0.05 \% \mathrm{MgSO}_{4}, 0.05 \%$ yeast extract, and $0.5 \%$ glucose $(\mathrm{pH} 6.0)$, they were incubated at $26^{\circ} \mathrm{C}$ with shaking at $120 \mathrm{rpm}$. The culture solution was filtered through a paper filter. The filtrate was used as a culture broth. 
After A. kawachii was inoculated into $100 \mathrm{~g}$ steamed rice, it was incubated at $28^{\circ} \mathrm{C}$ for $7 \mathrm{~d}$. The rice with mold was mixed with $1.4 \mathrm{~kg}$ steamed rice at $60^{\circ} \mathrm{C}$, spread thinly in a Tupperware ${ }^{\mathrm{TM}}$ vessel, covered by food wrap, and incubated at $28^{\circ} \mathrm{C}$. After $3 \mathrm{~d}$, the rice malt was mixed with $200 \mathrm{~g} \mathrm{NaCl}$. After it had been kept in a plastic barrel for $14 \mathrm{~d}$ at $23^{\circ} \mathrm{C}$ in the dark, it was used as a salted rice malt paste.

\section{Preparation of Pickled Ginseng}

Pickled ginseng was prepared by soaking $30 \mathrm{~g}$ of 1 -year-old and 6 -year-old ginseng in the salted rice malt paste. The paste was mixed briefly every $2 \mathrm{~d}$ and left in the dark at $23^{\circ} \mathrm{C}$ for $28 \mathrm{~d}$.

\section{Preparation of Ginseng Extract}

After $30 \mathrm{~g}$ of fresh 1-year-old and 6-year-old ginseng were minced and homogenized in $150 \mathrm{~mL}$ of $80 \%(\mathrm{v} / \mathrm{w})$ ethanol with a Waring blender, the solution was incubated at $80^{\circ} \mathrm{C}$. After $14 \mathrm{~h}$, the solution was filtered and evaporated to remove ethanol. The volume of the remaining solution was adjusted to $30 \mathrm{~mL}$ with distilled water. It was used as a ginseng extract. The pickled ginseng was washed with water to remove the malt paste. The extract was prepared as described above.

\section{Transformation of Ginsenosides by Culture Broth}

The mixture $(50 \mu \mathrm{L})$ containing $5 \mu \mathrm{L}$ of $\mathrm{Rb} 1$ solution $(50 \mu \mathrm{g})$ and $45 \mu \mathrm{L}$ of culture broth ( $6 \mathrm{mU} \beta$-glucosidase) or the mixture (100 $\mu \mathrm{L}$ ) containing $50 \mu \mathrm{l}$ of ginseng extract and $350 \mu \mathrm{l}$ of culture broth (44 mU $\beta$-glucosidase) was incubated at $37^{\circ} \mathrm{C}$ for 1,48 , or $96 \mathrm{~h}$. The reaction mixture was extracted with an equal volume of $n$-butanol. Then the $n$-butanol fraction was analyzed using HPLC.

\section{Enzyme Assay}

The $\beta$-glucosidase activities of the culture solution and salted rice malt paste were assayed using a colorimetric method using $p$-nitrophenyl- $\beta$-D-glucopyranoside (PNPG) as a substrate [26]. The reaction mixture $(1 \mathrm{~mL})$, which consists of $100 \mathrm{mM}$ acetate buffer ( $\mathrm{pH}$ 5.0), $5 \mathrm{mM}$ PNPG, and culture broth, was incubated at $37^{\circ} \mathrm{C}$ for $10 \mathrm{~min}$. The reaction was terminated by the addition of 2 $\mathrm{ml}$ of $1 \mathrm{M}$ sodium bicarbonate. The absorption at $400 \mathrm{~nm}$ was measured using a UV spectrophotometer. One unit of $\beta$-glucosidase activity was defined as the amount of enzyme liberating $1 \mu \mathrm{mol}$ $p$-nitrophenol per min.

\section{HPLC Analysis of Ginsenosides}

The ginsenosides were identified using an HPLC analysis system with a column $\left(4.6 \times 250 \mathrm{~mm}\right.$, Cosmosil $\mathrm{C}_{18}$; Nacalai Tesque Inc., Kyoto, Japan) heated at $40^{\circ} \mathrm{C}$. The mobile phase consisted of solvent A (water) and solvent B (acetonitrile) with a flow rate of $1.0 \mathrm{~mL} / \mathrm{min}$. The initial mobile phase composition of $20 \%$ solvent $\mathrm{B}(0-15 \mathrm{~min})$ changed linearly to $70 \%(15-30 \mathrm{~min})$. It was then followed by $100 \%$ (30-40 min). The effluent was monitored using a UV detector at $203 \mathrm{~nm}$.

\section{Results}

$\beta$-Glucosidase Activities in Culture Broth and Salted Rice Malt Paste

Aspergillus species of four kinds were cultivated in the medium with glucose as a carbon source. The $\beta$-glucosidase activities in the culture broths of $A$. oryzae, A. sojae, A. kawachii, and $A$. luchuensis were, respectively, 0.50, 0.61, 48, and $6.2 \mathrm{mU} / \mathrm{mL}$ after 8 d cultivation, $3.40,1.90,97$, and $34 \mathrm{mU} / \mathrm{mL}$ after $12 \mathrm{~d}$ cultivation, and $1.50,1.10,125$, and $43 \mathrm{mU} / \mathrm{mL}$ after $16 \mathrm{~d}$ cultivation. The juice of the salted rice malt paste fermented for $14 \mathrm{~d}$ was centrifuged at $15,000 \times g$ for $5 \mathrm{~min}$. The supernatant showed $165 \mathrm{mU} / \mathrm{mL}$ $\beta$-glucosidase activity.

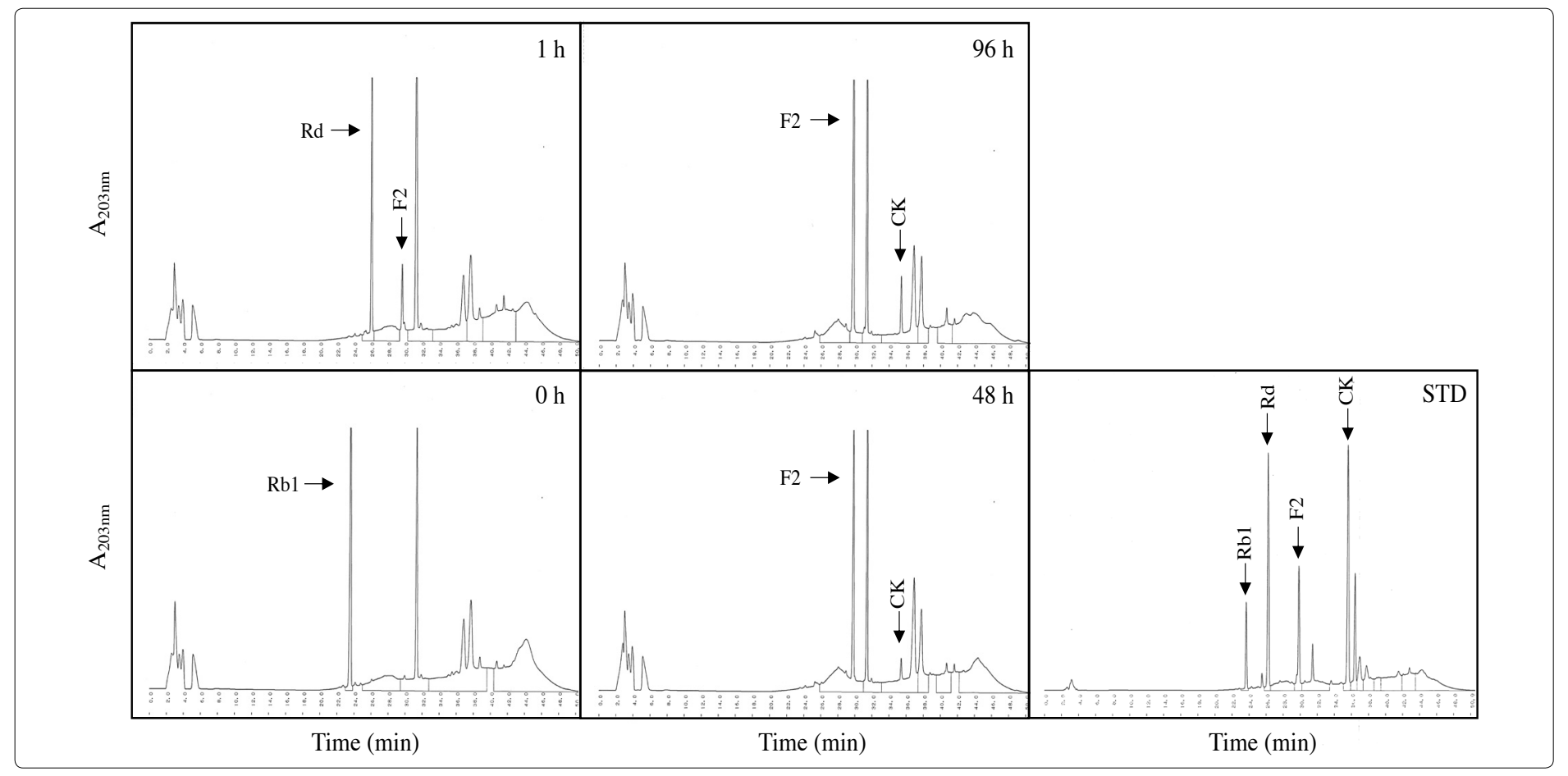

Figure 1: HPLC analysis of the transformation of Rb1 by culture broth of $A$. kawachii

The reaction mixture of $\mathrm{Rb} 1$ and culture broth of $A$. kawachii was incubated at $37^{\circ} \mathrm{C}$ for 1,48 , and $96 \mathrm{~h}$. The reaction mixture was extracted with $n$-butanol; $20 \mu$ of n-butanol fraction was injected. STD, standard mixture containing Rb1, Rd, F2, and CK. 
Transformation of Rb1 by Culture Broth

The transformation of Rb1 by the culture broth of A. kawachii was analyzed using HPLC (Figure 1). The peak of Rb1 disappeared. Also, Rd and F2 were generated after $1 \mathrm{~h}$, of which the level of Rd was higher than that of F2. After $48 \mathrm{~h}$, the peak of Rd disappeared, the level of F2 increased, and the peak of CK appeared. The level of CK was increased after $96 \mathrm{~h}$. The peak ratios of Rb1, Rd, F2, and CK after $96 \mathrm{~h}$ incubation were 0:0:83:17.
Transformation of Ginseng Extract by Culture Broth

Results of HPLC analysis revealed that the extracts 1-year-old and 6-year-old ginseng had Rb1 and Rd, but not F2 and CK. After $96 \mathrm{~h}$ incubation of the ginseng extracts with the culture broth of $A$. kawachii, $\mathrm{Rb} 1$ and $\mathrm{Rd}$ disappeared. Then $\mathrm{F} 2$ and $\mathrm{CK}$ were generated in both mixtures (Figure 2). The peak ratios of Rb1, Rd, F2, and CK before and after incubation of 1-year-old ginseng extract were 68:32:0:0 and 0:0:87:13, respectively. Those of 6-year-old ginseng extract were 72:28:0:0 and 0:0:83:17, respectively.

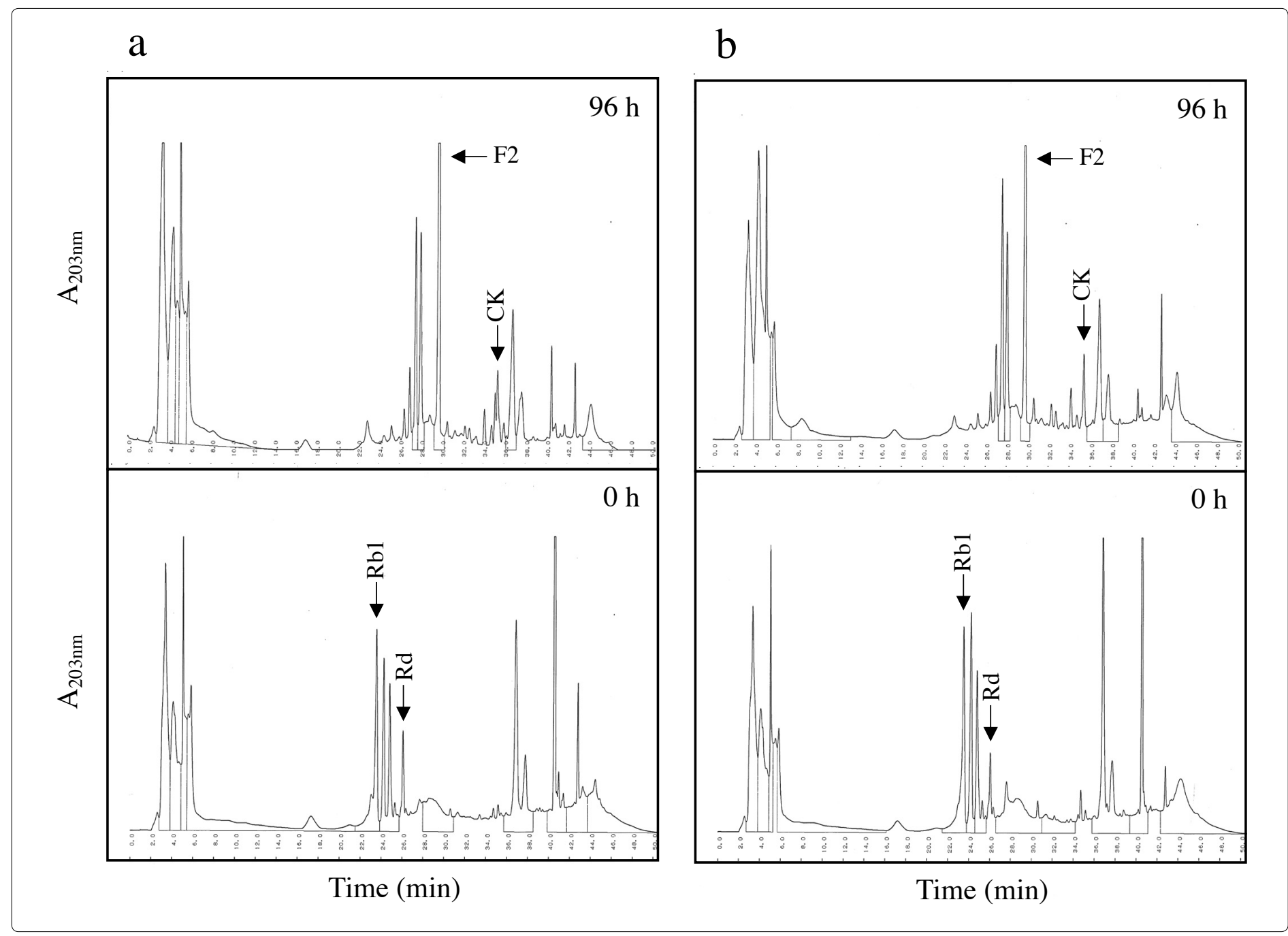

Figure 2: HPLC analysis of the transformation of ginsenosides of extract using culture

Extracts of 1-year-old (a) and 6-year-old (b) ginsengs incubated with the culture broth of $A$. kawachii were incubated at $37^{\circ} \mathrm{C}$ for $96 \mathrm{~h}$. The reaction mixture was extracted with $n$-butanol; $20 \mu \mathrm{l}$ of n-butanol fraction was injected.

\section{Salt Stability of $\beta$-Glucosidase}

The salt stability of $\beta$-glucosidase in the culture broth of $A$. kawachii was evaluated by incubation with $20 \%(\mathrm{w} / \mathrm{v}) \mathrm{NaCl}$ for 60 $\mathrm{d}$ at $25^{\circ} \mathrm{C}$. The enzyme activities were 117 and $117 \mathrm{mU} / \mathrm{mL}$ before and after $60 \mathrm{~d}$ incubation, respectively, showing that the enzyme is completely stable after $60 \mathrm{~d}$ at $20 \% \mathrm{NaCl}$.
Transformation of Ginseng by Salted Rice Malt Paste

The extracts of 1-year-old and 6-year-old ginsengs pickled in the salted rice malt paste for $28 \mathrm{~d}$ contained $\mathrm{F} 2$ and $\mathrm{CK}$ in addition to $\mathrm{Rb} 1$ and Rd by HPLC analysis (Figure 3). The ratios of Rb1, Rd, $\mathrm{F} 2$, and $\mathrm{CK}$ in the extracts of 1-year-old and 6-year-old ginseng roots were, respectively, 40:39:7:14 and 35:45:8:12. The respective amounts of $\mathrm{F} 2$ and $\mathrm{CK}$ in the 1-year-old ginseng pickled in the salted rice malt paste were 5.0 and $6.0 \mu \mathrm{g} / \mathrm{g}$; those of pickled 6-year-old ginseng were, respectively, 3.0 and $2.0 \mu \mathrm{g} / \mathrm{g}$. 


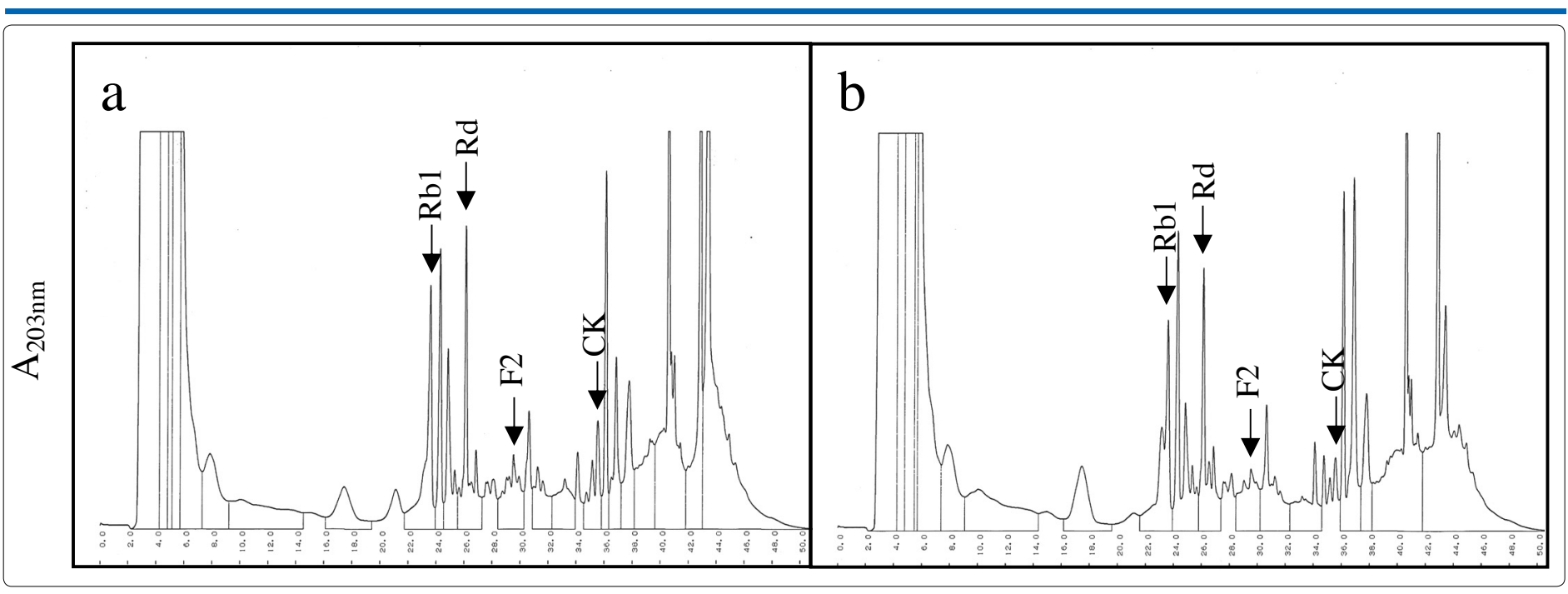

Figure 3: HPLC analysis of extracts of ginsengs pickled in the salted rice mold paste

Ginsenosides of the extracts prepared from 1-year-old and 6-year-old ginsengs pickled in the salted rice mold paste for $28 \mathrm{~d}$ were extracted with $n$-butanol; $20 \mu \mathrm{l}$ of $n$-butanol fraction was injected: (a) 1-year-old ginseng extract and (b) 6-year-old ginseng extract.

\section{Discussion}

Production of minor ginsenosides from major ginsenosides has been approached through the use of microbial and enzymatic reactions. Culture medium of $A$. niger, culture medium of $A$. oryzae, crude enzyme solution from recombinant Lactococcus lactis, purified $\beta$-glucosidase from Aspergillus sp, and purified $\beta$-glucosidase from $A$. niger transformed major ginsenosides to minor ginsenosides [21, 22, 27]. These methods require commercial or self-purified major ginsenosides as a substrate, or culture medium or purified enzyme solution. Therefore, they are limited by costs and the working process used for implementation. In addition, a risk exists of mycotoxin contamination because some microorganisms were not edible food microorganisms.

To enhance the contents of minor ginsenosides in ginseng at low labor and cost, we specifically examined Japanese traditional fermentation using "koji mold" and "nukazuke" for transforming ginsenosides in ginseng. Koji mold is used to produce various fermented food products such as sake, soy sauce, and miso. Koji mold produces enzymes such as glycosidases and proteases, which hydrolyze macromolecules such as starches and proteins. Nukazuke is a pickled vegetable in a fermented rice bran paste prepared by mixing rice bran and salt and by subsequent storage in a dark. The pickled vegetables are fermented by lactic acid bacterium and yeast grown in the past. The major ginsenosides are producible by hydrolysis of sugar moieties from the major ginsenoside using $\beta$-glucosidase. Therefore, koji mold is useful as an enzyme source. The nukazuke paste increases the permeability of the pickled vegetables and prevents the growth of toxic microbes. The combinations of the properties inherent in these two methods can change the contents of ginsenosides in ginseng because $\beta$-glucosidase excreted from koji mold permeates the ginseng and transforms major ginsenosides into minor ginsenosides while the ginseng is pickled in a rice malt paste fermented by koji mold.

To find the koji mold that excretes $\beta$-glucosidase, four typical microorganisms of koji mold, A. oryzae, A. sojae, A. kawachii, and $A$. luchuensis, which have been used respectively to produce sake, soy sauce, shochu liquor, and awamori liquor, were cultivated in the medium with glucose as a carbon source because steamed rice was used to produce a fermented paste. The $A$. kawachii culture broth showed the highest $\beta$-glucosidase activity after $16 \mathrm{~d}$, followed by that of $A$. luchuensis, of which the activity was about one-third that of $A$. luchuensis. The culture broths of $A$. oryzae and $A$. sojae showed maximum activities after $8 \mathrm{~d}$ and decreased thereafter. The broth concentrations were, respectively, about 1/37 and $1 / 66$ of the concentration of $A$. kawachii. These results indicate that $A$. kawachii produces extracellular $\beta$-glucosidase well in the medium and that it was useful to ferment the steamed rice.

The most abundant ginsenoside in the ginseng is Rb1, which usually accounts for more than $20 \%$ of total ginsenosides [5]. Transformation of $\mathrm{Rb} 1$ by $\beta$-glucosidase from microorganisms has been reported to occur by the hydrolytic pathways $\mathrm{Rb} 1 \rightarrow \mathrm{Rd} \rightarrow \mathrm{F} 2 \rightarrow \mathrm{CK}, \mathrm{Rb} 1 \rightarrow \mathrm{Rd} \rightarrow \mathrm{Rg} 3, \mathrm{Rb} 1 \rightarrow \mathrm{Rd}$, and $\mathrm{Rb} 1 \rightarrow$ gypenoside $\mathrm{XVII} \rightarrow \mathrm{F} 2$ [1, 12-16, 20-23]. The reaction of culture broth of $A$. kawachii demonstrated that $\mathrm{Rb} 1$ disappeared, that $\mathrm{Rd}$ and $\mathrm{F} 2$ had formed after $1 \mathrm{~h}$, that Rd disappeared, that the level of F2 increased, and that CK had formed by $48 \mathrm{~h}$; moreover, the level of $\mathrm{CK}$ had increased after $96 \mathrm{~h}$ (Figure 1). The change of ginsenoside contents that is variable in accompaniment to the passage of time suggests the hydrolytic pathway of $\mathrm{Rb} 1 \rightarrow \mathrm{Rd} \rightarrow \mathrm{F} 2 \rightarrow \mathrm{CK}$. To evaluate the inhibition of $\beta$-glucosidase activity by ginseng contents, the culture broths of $A$. kawachii were incubated with extracts of 1-year-old and 6-year-old ginseng. The Rb1 and Rd in both extracts disappeared; also, F2 and CK were formed after $96 \mathrm{~h}$, indicating that the enzyme can generate F2 and CK (Figure 2). These results suggest that the culture broth of A. kawachii can work to produce $\mathrm{F} 2$ and $\mathrm{CK}$ from $\mathrm{Rb} 1$ in ginseng.

High concentrations of salt in the paste are necessary to increase the permeability of the pickled vegetables and to prevent toxic microbe growth. After confirming that $\beta$-glucosidase in the culture broth of $A$. kawachii was completely stable after $60 \mathrm{~d}$ with $20 \%$ $\mathrm{NaCl}$, steamed rice was fermented by $A$. kawachii with $14 \% \mathrm{NaCl}$ to produce a salted rice malt paste as a pickle bed. The juice of the 
paste fermented for $14 \mathrm{~d}$ showed $165 \mathrm{mU} / \mathrm{mL} \beta$-glucosidase activity. Fresh 1-year-old and 6-year-old ginsengs softened when pickled in the paste after $28 \mathrm{~d}$. Whereas the extracts prepared from fresh ginseng showed peaks of Rb1 and Rd but not those of F2 and $\mathrm{CK}$, the peaks of F2 and CK appeared and those of Rb1 and Rd decreased in the extract of the pickled ginseng (Figure 3).These results suggest that the excluded $\beta$-glucosidase from $A$. kawachii permeated into the ginseng and transformed $\mathrm{Rb} 1$ and $\mathrm{Rd}$ into F2 and CK. The contents of F2 and CK in the pickled 1-year-old ginseng were higher than that of the pickled 6-year-old ginseng because the thinner shape and softer peel of 1-year-old ginseng than 6-year-old ginseng probably caused good permeation of $\beta$-glucosidase. Taken together, these findings demonstrate that pickling fresh ginseng in the salted rice malt paste is a simple and useful means of producing minor ginsenosides F2 and CK and changing the relative contents of Rb1, Rd, F2, CK in ginseng. Recently CK biosynthesis was achieved by introducing genes encoding enzymes that consist of CK biosynthetic pathway into Saccharomyces cerevisiae, Yarrowia lipolytica, and Nicotiana tabacum [28-31]. These methods are valuable to provide CK for the clinical application. Our pickled ginseng contains F2 and CK in addition to major ginsenosides, which show multifaceted pharmacological activities, while those amounts are small, therefore, it can be used effectively as a resource for dietary supplements, healthy foods, and functional foods [32].

Traditionally, fresh 4-, 5-, and 6-year-old ginseng are used to prepare processed products of ginseng, white ginseng, and red ginseng. White ginseng was produced by drying fresh roots under sunlight. Red ginseng is produced by steaming fresh roots and drying [33]. These processed ginsengs enhance the contents of minor ginsengs and increase their respective pharmaceutical activities [34]. Well-grown and healthy 1-year-old ginseng plants are cultivated to harvest 4-, 5-, and 6-year-old ginseng. After thinning, the remainder of 1-year-old ginseng is discarded or used as a material for eating. Our method of enhancing the minor ginsenosides in ginseng is pickling of ginseng in the salted rice malt paste. Especially, the CK production is expected to elicit biological activities just as it does for white and red ginsengs.

\section{Acknowledgments}

We thank Mr. Go Kadowaki, the president of Yuushien Agrifarm Co., Ltd., Shimane, Japan, for supplying 1-year-old and 6-year-old ginseng samples.

\section{References}

1. Ye L, Zhou CQ, Zhou W, Zhou, P, Chen DF, et al. (2010) Biotransformation of ginsenoside Rb1 to ginsenoside $\mathrm{Rd}$ by highly substrate tolerant Paecilomyces bainier 229-7. Bioresource Technology 101: 7872-7876.

2. Jia L, Zhao Y, Liang XJ (2009) Current evaluation of the millennium phytomedicine ginseng (II): collected chemical entities, modern pharmacology, and clinical applications emanated from traditional Chinese medicine. Current Medical Chemistry 16: 2924-2942.

3. Cheng LQ, Na JR, Bang MH, Kim MK, Yang DC (2008) Conversion of major ginsenoside $\mathrm{Rb} 1$ to 20(S)-ginsenoside Rg3 by Microbacterium sp. GS514. Phytochemistry 69: 218-224.
4. Li WK, Gu CG, Zhang HJ, Awang DVC, Fitzloff JF, et al. (2000) Use of high performance liquid chromatography tandem mass spectrometry to distinguish Panax ginseng C.A. Meyer (Asian ginseng) and Panax quinquefolius L. (American ginseng). Analytical Chemistry 72: 5417-5422.

5. Ji QC, Harkey MR, Henderson GL, Gershwin ME, Stem JS, et al. (2001) Quantitative determination of ginsenosides by high-performance liquid chromatography-tandem mass spectrometry. Phytochemical Analysis 12: 320-326.

6. Lee BH, Lee SJ, Hui JH, Lee SY, Sung JH, et al. (1998) In vitro antigenotoxic activity of novel ginseng saponin metabolites formed by intestinal bacteria. Planta Medica 64: 500-503.

7. Bae EA, Choo MK, Park SY, Shin SY, Kim DH (2002) Metabolism of ginsenoside Rc by human intestinal bacteria and its related antiallergic activity. Biological Pharmaceutical Bulletin 25: 743-747.

8. Nag SA, Qin JJ, Wang W, Wang MH, Wang H, et al. (2012) Ginsenosides as anticancer agents: In vitro and in vivo activities, structure activity relationships, and molecular mechanisms of action. Frontiers Pharmacology 3: 25.

9. Li HU, Bae EA, Han MJ, Kim DH (2005) Hepatoprotective effect of ginsenoside Rbland compound $\mathrm{K}$ on tert-butyl hydroperoxide-induced liver injury. Liver International 25: 1069-1073.

10. Park JS, Shin JA, Jung JS, Hyun JW, Van Le, et al. (2012) Anti-inflammatory mechanism of compound $\mathrm{K}$ in activated microglia and its neuroprotective effect on experimental stroke in mice. Journal Pharmacology Experimental Therapeutics 341: 59-67.

11. Su JH, Xu JH, Lu WY, Lin GQ (2006) Enzymatic transformation of ginsenoside Rg3 to Rh2 using newly isolated Fusarium proliferatum ECU2042. Journal Molecular Catalysis B: Enzymatic 38: 113-118.

12. Yu H, Zhang C, Lu M, Sun F, Fu Y, et al. (2007) Purification and characterization of new special ginsenosidase hydrolyzing multiglycosides of protopanaxadiol ginsenosides, ginsenosidase type I. Chemical Pharmaceutical Bulletin 55: 231-235.

13. Chi H, Kim DH, Ji GE (2005) Transformation of ginsenosides $\mathrm{Rb} 2$ and Rc from Panax ginseng by food microorganisms. Biological Pharmaceutical Bulletin 28: 2102-2015.

14. Hyun C, Lee BH, You HJ, Park MS, Ji GE (2006) Differential transformation of ginsenosides from Panax ginseng by lactic acid bacteria. Journal Microbiology Biotechnology 16: 16291633.

15. Cheng LQ, Na JR, Kim MK, Band MH, Yang DC (2007) Microbial Conversion of Ginsenoside $\mathrm{Rb} 1$ to Minor Ginsenoside F2 and Gypenoside XVII by Intrasporangium sp. GS603 Isolated from Soil. Journal Microbiology Biotechnology 17: 1937-1943.

16. Ko SR, Suzuki Y, Suzuki K, Choi KJ, Cho BG (2007) Marked production of ginsenosides $\mathrm{Rd}, \mathrm{F} 2, \mathrm{Rg} 3$, and compound $\mathrm{K}$ by enzymatic method. Chemical Pharmaceutical Bulletin 55: $1522-1527$. 
17. Yan Q, Zhou W, Li X, Feng M, Zhou P (2008) Purification method improvement and characterization of a novel ginsenoside-hydrolyzing $\beta$-glucosidase from Paecilomyces bainier sp. 229. Bioscience Biotechnology Biochemistry 72: 352-359.

18. Noh KH, Son JW, Kim HJ, Oh DK (2009) Ginsenoside compound $\mathrm{K}$ production from ginseng root extract by a thermostable $\beta$-glycosidase from Sulfolobus solfataricus. Bioscience Biotechnology Biochemistry 73: 316-321.

19. Quan LH, Cheng LQ, Kim HB, Kim JH, Son NR et al. (2010) Bioconversion of ginsenoside $\mathrm{Rd}$ into compound $\mathrm{K}$ by Lactobacillus pentosus DC101 isolated from kimchi. Journal Ginseng Research 34: 288-295.

20. Quan LH, Min JW, Jin Y, Wang C, Kim YJ et al. (2012) Enzymatic biotransformation of ginsenoside $\mathrm{Rb} 1$ to compound $\mathrm{K}$ by recombinant $\beta$-glucosidase from Microbacterium esteraromaticu. Journal Agricultural Food Chemistry 60: 3776-3781.

21. Chang KH, Jo MN, Kim KT, Paik, H.D (2014) Evaluation of glucosidases of Aspergillus niger strain comparing with other glucosidases in transformation of ginsenoside $\mathrm{Rb} 1$ to ginsenoside Rg3. Journla Ginseng Research 38: 47-51.

22. Liu CY, Zhou RX, Sun CK, Jin, YH, Yu HS, et al. (2015) Preparation of minor ginsenosides C-Mc, C-Y, F2, and C-K from American ginseng PPD-ginsenoside using special ginsenosidase type-I from Aspergillus niger g.848. Journal Ginseng Research 39: 221-229.

23. Upadhyaya J, Kim MJ, Kim YH, Ko SR, Park HW, et al. (2016) Enzymatic formation of compound-K from ginsenoside $\mathrm{Rb} 1$ by enzyme preparation from cultured mycelia of Armillaria mellea. Journal Ginseng Research 40: 105-112.

24. Park SE, Na CS, YooSA, Seo SH, Son HS (2017)Biotransformation of major ginsenosides in ginsenoside model culture by lactic acid bacteria. Journal Ginseng Research 41: 36-42.
25. Murooka Y, Yamshita M (2008) Traditional healthful fermented products of Japan. Journal Industrial Microbiology Biotechnology 35: 791-798.

26. Hang YD, Woodams EE (1994) Apple pomace: A potential substrate for production of $\beta$-glucosidases from different Aspergillus strains. Food Science Technology 27: 587-589.

27. Li L, Lee SJ, Yuan QP, Im WT, Kim SC, et al. (2018) Production of bioactive ginsenoside Rg3(S) and compound K using recombinant Lactococcus lactis. Journal Ginseng Research 2018: 412-418.

28. Yan X, Fan Y, Wei W, Wang P, Liu Q, et al. (2014) Production of bioactive ginsenoside compound $\mathrm{K}$ in metabolically engineered yeast. Cell Research 24: 770-773.

29. Nan W, Zhao F, Zhang C, Ju H, Lu W (2020) Promotion of compound $\mathrm{K}$ production in Saccharomyces cerevisiae by glycerol. Microbial Cell Factories 19: 41.

30. Li D, Wu Y, Zhang C, Sun J, Zhou Z, et al. (2019) Production of triterpene ginsenoside compound $\mathrm{K}$ in the non-conventional yeast Yarrowia lipolytica. Agricultural Food Chemistry 67: 2581-2588.

31. Gwak YS, Han JY, Adhikari PB, Ahn CH (2017) Heterologous production of a ginsenoside saponin (compound $\mathrm{K}$ ) and its precursors in transgenic taobacco impairs the vegetative and reproductive growth. Planta 245: 1105-1119.

32. Ratan ZA, Haidere MF, Hong YH, Park SH, Lee JO, et al. (2020) Pharmacological potential of ginseng and its major component ginsenosides. Journal Ginseng Research. https:// doi.org/10.1016/j.jgr.2020.02.004

33. Kim WY, Kim JM, Han SB, Lee SK, Kim ND, et al. (2000) Steaming of ginseng at high temperature enhances biological activity. Journal Natural Products 63: 1702-1704.

34. Lim CY, Moon JM, Kim BY, Lim SH, Lee GS, et al. (2015) Comparative study of Korean white ginseng and Korean red ginseng on efficacies of OVA-induced asthma model in mice. Journal Ginseng Research 39: 38-45. 